\title{
La discriminación
}

\author{
ENRIQUE LYNCH \\ Universidad de Barcelona
}

Concentro la atención en lo que oigo.

Una bocina estridente atraviesa el cristal de la ventana desde la calle. Tras ella llega el ruido de un camión que descarga, y muy cerca de donde estoy sentado, el zumbido del ordenador, que suena todo el tiempo.

¿Qué más siento? Innumerables señales del cuerpo que puedo discriminar una tras otra, con sólo atenderlas con cuidado. Me parece que, si me lo propusiera, podría fijar el punto de mi cuerpo donde las siento. Cada una de ellas se me representa como un pequeño dolor localizado y podría servir además como testigo del cuerpo. El ruido que oigo también es dolor, pero una convención me permite interpretarlo como un objeto distinto de mis sensaciones corrientes. El dolor, cualquiera que sea, es un medio de comprobar que mi cuerpo está aquí, acompañando mi pensamiento.

Pongo en funcionamiento un aparato, una fuente cualquiera de sonido que emite una señal, y ésta se suma al contexto sensible como un estímulo más. No parece haber diferencias apreciables entre los sonidos organizados que forman la señal del aparato -lo que llamamos música-y el resto de los estímulos. Aunque he sido adiestrado para discriminar entre los dolores y darles un valor positivo o negativo en términos de 'placentero' o 'no placentero', si los considero desde una impostada frialdad y distancia, me parece que todos estos dolores son lo mismo: sensaciones, unas más opacas o menos significantes que las otras. No puedo decir que lo sé pero estoy casi seguro de que la diferencia no está en una naturaleza específica de las sensaciones sino en mi disposición hacia ellas. Si profundizo esa reflexión comprendo que quiero pensar que es así, contra mi formación e información sensoriales que me enseñan a distinguir entre ellas. Comprendo que soy yo quien las resalta y se ocupa de ellas, lo que da pábulo a la tesis estética que jerarquiza las diferentes experiencias subjetivas sensoriales sólo por la disposición o la actitud del sujeto.

Según su naturaleza más elemental, toda sensación es pura y simplemente un cambio en el sistema del cuerpo o de algunas de sus funciones. Pero esencial a ese cambio somático es que uno sea conciente de ello. Dejo a un lado lo 
difícil que es establecer qué significa en este contexto 'conciente'. Igual que sucede con el pensamiento, la memoria o la imaginación, la sensación tiene una explicación fisiológica pero sólo un materialista dogmático e intransigente se quedaría satisfecho con reducirla, en tanto que acontecimiento, a un inexplicable epifenómeno de procesos químico-moleculares que tienen lugar en el nivel del cuerpo. Es preciso que, para referirme a ella, la sensación sea un objeto de la conciencia, pero que algo sea objeto de la conciencia, no es suficiente para que creamos en ello. A diferencia de la función racional, que en alguna medida justifica la idea de que hay un mundo allí fuera, lo que llamamos tener una sensación no viene acompañado de ninguna convalidación ontológica. ¿Por qué he de pensar que esa experiencia íntima del mundo es mundo si sólo es para mí? La tengo, inequívocamente, pero -a diferencia de lo que sucede con el raciocinio- no puedo comunicarla, ni describirla. Por lo tanto, si es inaccesible a los demás, ¿por qué habría de pensarla como legítima? Todo lo que digo acerca de ella es pobre, o impreciso, o falaz, o simplemente, aproximado. De tal modo que el otro sólo puede trazar una conjetura acerca de lo que yo siento, asunto de formidable complejidad que ninguna racionalización puede dar por zanjado. Primero, porque no hay en la sensación un pensar puro sino que hay intervención del cuerpo: la parte de mí mismo que no controlo ni conozco más allá de los signos vagos que recibo en forma de dolor o de pequeños o grandes desequilibrios somáticos. Y, por otra parte, sé de mi cuerpo no por representaciones conceptuales que puedo cotejar con la opinión de otros sino tan sólo por un número indeterminado de síntomas que sólo yo conozco. Los síntomas (el síntoma es la señal de que hay algo significante) son mi cuerpo, pero mi cuerpo es sólo mío.

Sé que todos estos argumentos son solipsistas y que hay una frondosa literatura que descalifica el solipsismo, pero ninguna de sus alegaciones consigue desembarazarme de la apabullante certeza de la sensación. En otras palabras: descubrirme atrapado en las ilusiones del solipsismo no me libera de su influencia sino que, curiosamente, me hace sospechar que los argumentos que lo desacreditan, por autorizados que sean, son meras racionalizaciones. $\mathrm{Y}$ en cierto modo, me exaspera: ¿qué sentido tiene razonar contra lo que uno siente o experimenta? En algún fragmento cuya referencia no puedo encontrar Nietzsche anota que, contra toda razón o argumento y contra la experiencia de Colón, la Tierra no es redonda sino plana.

Segundo, la intervención del cuerpo pone en juego sentimientos movidos por sus sensaciones. No existe un lenguaje para tales sentimientos, y si lo hay, es un lenguaje privado. Igual que sucede con el solipsismo, también hay innumerables argumentos contra el lenguaje privado. Sin embargo, los mismos que descalifican el lenguaje privado -Wittgenstein, entre los más respetables de ellos- no dudan de que haya arte y artistas, aunque no puedan dar una definición de arte y tampoco puedan casi nunca saber qué quieren decir los artistas 
cuando se proponen interpretar el arte. No obstante, los críticos del solipsismo gozan con el arte solipsista y no suelen desacreditar a los artistas que incurren en falacias lógicas.

Tercero, como no hay gramática ni regla para la atención que pongo en mis sensaciones, puedo hacer con cada sensación lo que me plazca, incluso no comunicarla y permanecer encerrado con/en ella, como si fuese un autista. Puedo quedarme en silencio, confundido con/en lo que siento. El autismo es como la falta de sentido: la alternativa absoluta. Siempre es posible invocarlo como conducta válida, tanto como siempre es posible pensar que un acontecimiento del mundo carece de explicación razonable. El autismo es una condición terrible pero enormemente interesante y algo me dice que contiene el secreto de la conciencia.

Pongo especial atención en mis sensaciones. ¿Cómo es esa atención? Cada sensación conlleva, por un lado, una excitación nerviosa que sirve a la mente para dar cuenta del estímulo. Pero, por otro lado, la excitación nerviosa que mueve la sensación nunca llega sola sino acompañada de una sombra en el nivel de la conciencia, por llamar de algún modo, usando una metáfora elemental, a la típica referencia que el sujeto hace con relación a lo que experimenta. Puedo sentir y, al mismo tiempo, saber que siento, o imaginarme separado de mi sensación. Esa es mi conciencia. ¿Qué es, si no, declararse ‘enamorado’ o 'aterrorizado' o ‘enfermo de indignación' o ‘entusiasmado y traspuesto' por alguna cosa? Una sensación es un estímulo atendido, interpretado, elaborado de algún modo en la conciencia.

Parece claro que este proceso es del todo contingente, que puede o no producirse - puesto que hay una mayoría de individuos que jamás son concientes de nada de lo que les sucede en el nivel del pensamiento o de la sensación- pero, cuando se produce, la elaboración de la sensación, incluso si la pensamos como simple referencia, tiene lugar para el sentiente como si, por añadidura, dicha elaboración formara parte de la experiencia en sí, y no obstante queda registrada en la conciencia como algo ajeno a ella. Digo que es sombra, porque la sombra para una conciencia ingenua es por un lado parte de la cosa, y por otro, también es un mero efecto de la luz. Sin embargo, la presencia de esta 'sombra' es útil para mi conocimiento de la experiencia somática porque me permite discriminar entre la experiencia y el saber o la conciencia de ella, entre el acontecimiento experiencial y su rastro en la conciencia. Esto es lo que reconocemos empíricamente como ‘sensación'. O sea que sólo podemos hablar de 'sensación' cuando nos hallamos de algún modo libres de estimulación, cuando hemos discriminado entre el estímulo y su sombra en la conciencia, discriminación que cada uno hace a su modo y que sin demasiadas dificultades compartimos con los demás, pese a que este es un problema insondable al que Kant procuró dar explicación trascendental en la Crítica de la facultad de juzgar con un enrevesado modelo del pensar reflexionante que ha supuesto un 
quebradero de cabeza tremendo para toda la tradición estética posterior. Entre otras razones porque, que un cambio físico -que además es somático- pueda ser interpretado a título de una aisthēsis, bien puede ser condición suficiente (aunque sólo de facto) para que podamos hablar de algo como estético pero, por cierto, no es suficiente (de iure) para que la estética quede legitimada como disciplina. La estética nace como disciplina autónoma en virtud de la reflexión kantiana, pero con la salvedad apuntada: ¿por qué hay que discriminar entre un conocimiento de verdad y otro que sólo se funda en sensaciones subjetivas? ¿Por qué considerar diferentes las representaciones diáfanas (las que podemos compartir racionalmente con los demás) y las representaciones 'opacas', es decir, esas que vienen acompañadas de una sombra que sólo nosotros llegamos a tener? El pensamiento es uno solo.

Sea desde la epistemología o desde la estética, merece la pena apuntar que la probable discriminación entre el dolor y su sombra, en la sensación, algunas veces es la experiencia misma. Así, el caso de la música que, según Nietzsche, es «un lenguaje capaz de una discriminación infinita». ${ }^{1}$

Trátase, pues, de concentrar el análisis en la peculiaridad de esa experiencia estética musical que discrimina, siempre y cuando aceptemos que llamamos 'estética' a una sensación reflexiva que podríamos definir, con las reservas y matices del caso, como aquel acontecimiento del cuerpo en que un sujeto se siente dentro de una experiencia, como si formara parte de ella. En relación con la música, sobre todo cuando es particularmente intensa, nos comportamos como el autista, único protagonista de lo que siente, pero a diferencia de éste, estamos en condiciones de observarla -o de observarnos como sujeto de tal experiencia (lo que no sabemos si hace el autista)- desde un exterior virtual, conciente, racionalizable y hasta cierto punto discreto. Cuando pensamos la experiencia de la música de este modo nos parece un juego de sombras chinescas, puesto que en la música, puedo elaborar o modalizar con mi reflexión lo que siente mi cuerpo del mismo modo que, en el juego de las sombras chinescas, puedo modificar lo que veo jugando con las siluetas que mis dedos dibujan sobre una pared. Y, nótese además, que la naturaleza de tal experiencia sólo puede ser abordada a condición de que el sujeto haya sido debidamente convalidado como eje, vértice o punto de referencia insoslayable de la filosofía.

¿Qué puede querer decir aquí 'discriminar'? Por un lado que en la música hay cierta precisión en la experiencia. Que algo se da inequívocamente, sin confusión posible. Por otro lado, significa que musicalmente, de acuerdo con la

${ }^{1}$ La cita exacta es: «Die Musik ist eine Sprache, die einer unendlichen Verdeutlichung fähig ist. Die Sprache deutet nur durch Begriffe, also durch das Medium des Gedankens entsteht die Mitempfindung. Dies setzt ihr eine Grenze» KSA II 47: 2[10]. «La música es un lenguaje capaz de una discriminación infinita. El lenguaje explica sólo a través de conceptos, de tal modo que por medio del pensamiento surge la simpatía. Esto supone un límite para el lenguaje». 
fenomenología de tal experiencia, nos resulta relativamente más fácil separar la sensación del mero registro somático de la sensación. Por ejemplo, que una cosa es la música y otra diferente el sonido (algo que los músicos electroacústicos contemporáneos no tienen muy claro). Reflexionamos como si nos fuera posible franquear el límite de la inmediatez sensorio-perceptiva que necesariamente gobierna todas las sensaciones. Pero esto es participar, por decirlo a la manera de Wittgenstein, en un juego de lenguaje diferente, para el cual, dicho sea de paso, hemos sido convenientemente adiestrados. Sólo entonces, escuchar música se parece a la experiencia de otras sensaciones. Si no, como afirmaba Jankélévitch, la música se convierte para nosotros en una experiencia inefable.

Pensemos en una experiencia visual. Consideremos por ejemplo, un rojo intenso, abrumador, inequívoco. La 'sensación' (aisthēsis) de ese rojo sólo puede decirse que acontece cuando el sujeto es capaz de sentirlo como intuición propia, experiencial, y como color -o como signo asociado al color-; o cuando es capaz de discriminar (y subrayo aquí el uso de este verbo) entre el rojo que ve y el contenido significante del rojo, separando el sentido de sus implicaciones y valores, sus dimensiones asociadas, sus aplicaciones cromáticas y su gama de matices, usos, valores, etc. En suma, entre el rojo como acontecimiento y lo que el rojo quiere -o podría querer- decir. Por ejemplo, entre el rojo y su condición de color o de propiedad de una extensión, el rojo que actua como cualidad primaria o secundaria de una cosa. En tanto que información, todo lo que el rojo pueda sugerirnos estará dado en y por la experiencia sensorial pero, además y sobre todo, por la reflexión que nos sea posible hacer sobre ella.

Observo que el estímulo cromático es inequívocamente mío, pero sobre todo lo es la reflexión que lo acompaña, que es privada. De nuevo nos topamos con el arte, que sirve para desarticular la torpe seguridad de mis racionalizaciones. Puedo argumentar que siempre habrá un juego de lenguaje detrás de una reflexión privada pero resulta que, cuando se trata de una obra de arte, sólo el artista conoce las reglas de ese juego: nosotros sólo las conjeturamos.

Entre las cosas que el sujeto podría hacer con esa sensación está, por supuesto, la de considerar la experiencia de ese rojo como sensación. Parece evidente que, cualquiera que sea la índole del juicio que suscite una sensación, para reconocerla como tal es preciso trascender el horizonte que marca la percepción en sí. Lo cual plantea una paradoja a primera vista insalvable, ya que si bien la sensación existe en virtud del juicio a que da lugar, también existe en cuanto que mero acontecimiento para el sujeto que la experimenta. Y dicho acontecimiento -de nuevo para el sujeto- no se confunde con su juicio o interpretación sino que resulta, en virtud de la facultad de juzgar, de la discriminación señalada. Si puedo separar el rojo sentido del rojo reflexionado debería poder describir las condiciones que hacen a uno diferente o distinto del otro, debería poder hablar de uno y otro, pero lo cierto es que sólo puedo hablar de mi reflexión. Lo otro, lo que la suscita, el rojo, pese a que muchas veces tiene un contorno definido, 
no puedo describirlo. Aquí hay un límite descorazonador porque implica que infinidad de acontecimientos que son 'del mundo' porque tienen lugar en mi cuerpo, no están en el mundo.

No obstante, esta limitación no presupone descrédito de mi capacidad de juzgar y de comunicar mis juicios. ¿Cómo puede uno sentir algo y, en el contexto mismo de esa sensación, sobreponerse a los efectos de la propia sensibilidad con objeto de explicar racionalmente lo que está sintiendo? Los epistemólogos sugieren el uso de criterios, cualquiera que sea el sentido que dé a tales 'criterios', que son objetos ideativos no conceptuales. O, si no, sostienen que, para explicar lo que siento siempre se puede emplear un lenguaje gestual u ostensivo. De nuevo nos encontramos con el arte. El artista traspone a un gesto que puede, o no, plasmarse en una obra imperecedera, lo que siente, pero muchas veces -por no decir siempre- esa trasposición es ininteligible. Por otra parte, la ostensión es una herramienta comunicativa muy poco fiable y rudimentaria. A través de un gesto puedo entender que un individuo tiene o siente hambre porque se lleva la mano a la boca y mastica, pero desde luego no puedo saber qué le apetece. Y, por lo demás, tratándose de 'gestos', ¿qué significa el gesto de Marcel Duchamp cuando se lo conoce a través de una composición tan poco diáfana como es la célebre Le Grand Verre?

Si lo pensamos bien, comunicar una sensación es tan inverosímil como narrar una ensoñación al mismo tiempo que tiene lugar el sueño. Si fuera posible colocar narración y ensoñación en el mismo nivel comunicativo, como si fueran una misma cosa, entonces no haría falta narrar nada y la comunicación de un sueño debería convertirse en una lisa y llana invitación a soñar. Más que un sueño se trataría de una experiencia compartible, sin más. El sueño se presenta como un objeto independiente para el sujeto que lo narra, pero en realidad es un típico producto de la reflexión; más exactamente, de la reconstrucción narrativa de los elementos oníricos que guarda la memoria. 'Sueño' es la anamnēsis de una experiencia pasada, es decir el recuerdo de algo soñado; cuando menos, un subproducto de una actividad poética autónoma que tiene a la ensoñación como motivo o pretexto pero que no puede invocar referencia objetiva convalidante alguna. El sueño no es un objeto sino una extensión del sujeto -como lo es, por otra parte, la sensación discriminada en la música-, es decir, una experiencia sensorial reflexionada en la que intervienen los sentimientos. Por generalización podríamos incluir muchas otras experiencias semejantes: escenarios de terror donde se trata de describir el miedo que se experimenta, la impresión que causa una obra arte, la angustia, la genialidad de una jugada o la jugada en sí, si se ejecuta -por ejemplo- en el marco de un juego abstracto.

¿Y por qué no incluir también el deseo entre las experiencias sin objeto?² ¿Puede el deseo invocar algún tipo de objetualidad? No. Y sin embargo pocas experiencias hay que sean más tangibles que el deseo. La fijación de un objeto 
para el deseo, según la teoría freudiana, no nace de la pulsión en sí sino de la represión, es decir que es un subproducto cultural.

En el caso de los sueños parece evidente que de ellos sólo guardamos su versión narrada y, si acaso, su interpretación, pero ésta, de nuevo, también es narrativa. Lo mismo podría decirse de cualquier experiencia, cualquiera que sea su naturaleza o su contexto. La experiencia no puede ser si no una reconstrucción mnémica y, por eso mismo, una elaboración. De nuevo tenemos ante nosotros el arte: parece evidente que se necesita contar con alguna pericia artística para narrar un sueño. $\mathrm{O}$ incluso para poder compartir nuestras sensaciones.

Cabe la posibilidad de que esa experiencia, tenida como cambio de estado del sujeto, sólo sea expresada, como, por ejemplo, cuando estallamos en carcajadas. La risa es expresión de un estado subjetivo de alegría, pero ¿cómo sabe el otro que esa expresión se corresponde en verdad a un estado de alegría? ¿Cómo puede saber si no estoy tan sólo simulando la risa? ${ }^{3}$ La expresión no es comunicación, entre otras razones, porque en ella sujeto y objeto se confunden. Argumento escéptico que sin duda puede extenderse a toda experiencia si nos atenemos al modo estricto en que la experiencia tiene lugar. Hecho denegado que, no obstante, cuestiona de raíz el valor crítico de la interpretación de los sueños o que, en última instancia, circunscribe el marco de convalidación de la interpretación de un sueño a la capacidad de persuasión del discurso narrativo que sirve para interpretarlo; en suma, remite a cierta eficacia retórica. Y, por cierto, hay un estilo que identifica al relato de un sueño y que nos permite sugerir que un cuento, o el pasaje de una novela, o una escena pintada o filmada, son oníricos aunque -paradójicamente- nada los distinga de un relato realista. El estilo de un relato nos sirve para reconocer que la narración de un sueño está ocupando el lugar de un objeto imposible, el sueño en sí, que inevitablemente se revela como constructo.

No. Si experimento una sensación -tanto como si sueño- no puedo dar cuenta de ella sino, cuando mucho, recordarla, reconstruirla, recrearla poética o prosaicamente, pero en cualquier caso, lo hago interponiendo un dispositivo o un artefacto entre la experiencia en sí y su referencia comunicable. Como con los sueños, digo o expreso o manifiesto o elaboro algo acerca la expe-

${ }^{2}$ Jean-Luc Nancy apunta: «Pero si el deseo es doble, la carencia en él es tanto la apertura de su impulso como el empuje de su infatigable tensión, una consideración. Si carece, es de nada: es decir, de ningún objeto, pues todo es sujeto para él. El sujeto deseante no puede referirse sino a un sujeto, él mismo deseante. Sin duda, éste es el sujeto que falta a su propia sustancia o a su propia presuposición: pues es el sujeto que se adelanta a sí mismo» Nancy, J.-L. 2003: 43.

${ }^{3}$ La situación puede llegar a ser dramática cuando se trata de dilucidar (o discriminar) si un orgasmo femenino es real o fingido. La endeblez de los criterios observacionistas propuestos por la denominada psicología cognitiva quedaba perfectamente ilustrada en aquel episodio de la película When Harry met Sally de Rob Reiner, con guión de Nora Ephron (1989), en que Meg Ryan (Sally) simula a la perfección los signos visibles de un orgasmo sentada a la mesa de una cafetería delante de su compañero de reparto Billy Crystal (Harry). 
riencia estética, pero sólo en la medida en que he conseguido sustraerme de algún modo a ella, para desembarazarme de sus efectos y trasponer el marco excluyente de mi percepción, contrariando al cuerpo. Sólo por convención doy como representación válida de esa experiencia la versión reconstruida de ella a través del lenguaje. Y por convención pienso esa representación discursiva como compartible por los demás, como una pieza inteligible, sujeta a razón común. He aquí el misterio de la mónada y del leibniziano sistema de mónadas que formamos, que únicamente tiene consistencia si se propone para ella una probable, pero no segura, dilucidación estética. Y, por lo demás, razón suficiente de que algunos filósofos de la tradición analítica (George Dickie y sobre todo Nelson Goodman) nieguen toda consistencia a la llamada 'experiencia estética' o que, como hace Goodman al comienzo de Languages of Art adviertan que lo que dicha experiencia sea en realidad no es materia de análisis filosófico sino, quizá, una cuestión que sólo puede resolver una adecuada psicología de la percepción. ${ }^{4}$

Ni qué decir tiene que, si seguimos esta línea de pensamiento, estamos abocados a considerar como falsarias o inauténticas todas las elaboraciones basadas en experiencias fundadas en sensaciones, por sesudas o autorizadas que sean. En ningún ámbito el escamoteo de la experiencia por su versión poetizada es tan evidente como en el arte o, más precisamente, en cierta crítica cuando se aplica a comentar obras de arte, ya sean contemporáneas o de cualquier otro tiempo. Sobre todo cuando echa mano del característico discurso impresionista que da a la jerga profesional su sello inconfundible. Por ejemplo cuando, en un alarde de exquisitez impostada, el crítico se aprovecha de la licencia poética que habilita a su discurso y se pone a hablar de 'cromatismos' en música o de 'intensidades matéricas' en pintura o de la 'transparencia del volumen' en arquitectura o de 'lirismo acerado' en poesía. Lo que este tipo de expresiones tiene de inconsistente no es únicamente el tono de camelo, la flagrante pedantería y el trasiego de clichés que es tan habitual en el género y que está presente, por otra parte, no sólo en la crítica sino en la filosofía de todos los tiempos, sino el hecho de que revela la necesaria disociación entre experiencia y razón, lo cual hace que toda 'crítica de arte', en cuanto que desarrollada como pretendida racionalización de una aisthessis, se convierta inevitablemente en puro palabrerío.

Tenemos, pues, un problema muy difícil. Hay una experiencia (típicamente estética) que, puesto que es sensación -es decir, hace intervenir los sentimientosno puede ser comunicada. ¿Cuál puede ser su legitimidad como experiencia? ¿Cómo sé ya no que el rojo que el otro ve es el mismo rojo que yo veo sino que el otro ve, en verdad, un rojo, si el único elemento de prueba con que cuento es su propia descripción de esa experiencia? Donald Davidson y muchos otros filósofos de la tradición llamada analítica responden invariablemente: «Lo sé

${ }^{4}$ Goodman, N. 1976. 
porque imagino que su experiencia debe de ser semejante a la mía en similares circunstancias»; es decir, creo que el otro ve un rojo porque veo, compruebo o colijo que sus respuestas en el nivel de la conducta explícita manifiesta son análogas o semejantes a las mías en iguales circunstancias. Naturalmente, los argumentos de Davidson ${ }^{5}$ sirven para explicar -aunque sea a medias- el rojo, pero ¿cómo sé si ella me quiere? Davidson respondería: «Lo sé porque ella se comporta como yo mismo cuando quiero a alguien». Pero esta respuesta es poco satisfactoria para el enamorado: ¿y si no se comporta como yo cuando estoy enamorado acaso debo concluir que no me quiere? La verdad es que la fórmula de Davidson nos deja en una posición muy poco airosa. $\mathrm{O}$ bien hemos de inclinarnos por la solución del neurótico obsesivo ( «Sé que ella me quiere porque yo la quiero»; o por una solución mucho más arriesgada aún: «Sé que me desea porque yo la deseo») que puede tener consecuencias imprevisibles. $\mathrm{O}$ bien hemos de admitir que la pregunta del enamorado ('¿Cómo sé que ella me quiere?') está condenada a quedar sin respuesta o que la observación de una conducta no basta para tranquilizar una conciencia atribulada. En cualquier caso, de lo que no cabe duda es que Davidson nunca ha estado enamorado.

Cuando se trata de considerar una experiencia de las llamadas privadas -y toda 'experiencia estética' lo es- nos encontramos con la misma dificultad descrita por Gilbert Ryle en el siguiente caso ${ }^{6}$.

Dos compañeros de curso guiñan el ojo derecho. Uno, llamado Pérez, lo hace porque tiene un tic involuntario, y el otro, Fernández, lo hace con intención de establecer algún vínculo conspirativo con un amigo. Observados desde el objetivo de una cámara fotográfica ambos guiños son idénticos en tanto que movimientos (facta) de modo que resulta imposible establecer cuál es cuál. Sin embargo, aunque está claro que hay una enorme diferencia entre ambos gestos esa diferencia no puede ser apreciada objetivamente, cosa que ha podido comprobar cualquiera que haya confundido un tic con un guiño de complicidad. Uno de ellos, Fernández, comunica (¿expresa?) algo en particular y lo hace de acuerdo con las siguientes pautas:

1) deliberadamente

2) a alguien en particular

3) con un mensaje

4) de acuerdo con un código preestablecido

5) sin conocimiento de los demás

Parece evidente que, como apunta Ryle, Fernández, al guiñar el ojo, hace cuando menos dos cosas: contraer el párpado y emitir una señal, mientras que Pérez hace una sola: parpadear de forma compulsiva. El de Fernández es un gesto, es decir, la combinación de un código con una cultura o, para ponerlo en

${ }^{5}$ Cf. Davidson, D. 2003.

${ }^{6}$ Gilbert Ryle, citado por Geertz, C. 1988: 21-22. 
los términos del llamado segundo Wittgenstein, una combinación de signos que resulta significativa dentro de un determinado juego de lenguaje. Hete aquí que aparece un tercer protagonista, llamado Rodríguez, que se pone a remedar los guiños de Pérez pero de forma desmañada, exagerando el gesto con objeto de divertir a sus compañeros. También aquí hay un mensaje (código+cultura, signo + juego de lenguaje) pero ahora no hay conspiración o movimiento compulsivo alguno sino una actitud de mofa, de burla o de poner en ridículo a alguna persona. Si sus compañeros piensan, desde fuera, que su gesto es un guiño, la tentativa burlona de Rodríguez fracasa por completo; aunque también fracasa si piensan que está mostrando un tic, pero por razones diferentes. Incluso puede ocurrir -sugiere Ryle- que nuestro Rodríguez, dudando de su capacidad de imitar los guiños de Pérez y Fernández, se ponga a ensayar delante de un espejo el gesto que ha observado en sus compañeros. En tal caso, Rodríguez ni estaría mostrando un tic, ni estaría haciendo un guiño, como tampoco estaría remedando a sus compañeros, pero una cámara, o un behaviorista radical o un fanático de los protocolos, creerá que Rodríguez está contrayendo un párpado, como hacen sus compañeros Pérez y Fernández. Ryle complica aún más la cosa e imagina que Fernández no guiñaba el ojo como señal de una conspiración en marcha sino que sólo simulaba hacerlo. Si fuera así, Rodríguez remedaría algo que no es lo que piensa, de manera que también cambiarían nuestras explicaciones acerca de lo que Rodríguez ensaya delante del espejo.

Por consiguiente hay, como mínimo, dos descripciones posibles acerca de lo que hace Rodríguez: una, que es superficial («Rodríguez parpadea»); y otra, que es densa (broad): «Rodríguez se burla de un amigo simulando que guiña un ojo para hacer creer a un inocente que está en marcha una conspiración». Geertz concluye que la segunda es el objeto y propósito de la etnografía puesto que ésta consiste en una estratificación jerárquica de estructuras significativas que sirven para producir, interpretar y percibir las relaciones entre guiños, tics, guiños fingidos, parodias, etc. independientemente de lo que se haga con los párpados.

Sin duda he aquí un problema mayor de los etnógrafos a la hora de confirmar sus hipótesis sobre la conducta de los individuos y las sociedades que observan, pero también un problema localizable, por otra parte, en muchos otros ámbitos en los que se trata de interpretar un hecho del que tenemos noticia solamente por la manifestación superficial de unos signos. Si la naturaleza artística de un objeto queda determinada por la intención artística de quien lo ha producido ¿cómo puedo saber que esa intención es verdadera o fingida si de ella sólo considero los gestos o declaraciones del artista? Igualmente por lo que toca a la realidad o a la naturaleza de toda 'experiencia interior', sea o no estética. Nos encontramos de nuevo en una encrucijada escéptica y no podemos si no dar la razón a Lacan cuando afirmaba provocativamente que la única prueba de la existencia de una 'vida interior' de un individuo era, por desgracia, las heces de éste. 
Análogamente al problema planteado por Ryle, llegar a captar las relaciones entre los diferentes estratos simbólicos y sígnicos es lo mismo que interpretar lo que una música quiere expresar.

Los románticos más respetables -o sea, los jóvenes del llamado Círculo de Jena reunido en torno a las enseñanzas de Fichte- encontraban una vía de escape a la paradoja afirmando que, por ejemplo, el arte, donde la sensación autoconciente, reflexiva o discriminada tiene lugar todo el tiempo, es una forma de conocimiento. Conocimiento que, por lo demás, en la medida en que es extático, trasciende las limitaciones de la apariencia y se eleva a la condición de conocimiento directo, inmediato, de lo en sí o Absoluto. No en vano la apariencia sensible era pensada como causante de la distinción entre sensación y conocimiento (o razón) de esa sensación. Así la distinción entre poesía ingenua y sentimental de Schiller, donde la segunda viene a ser como la Poesie der Poesie de Friedrich Schlegel, una poesía que es conciente de serlo. En esta dimensión del arte, el arte puede no tener objeto pero siempre es conocimiento de algo; cuando menos, del arte mismo, de ahí que Schelling afirmara que los signos artísticos son en definitiva tautagóricos, puesto que, a falta de un referente explícito, trazan alegorías de los propios signos alegorizantes.

Ser conciente de una experiencia sensible -o sea, reflexionar sobre ella- es, en este enfoque, la clave para discriminar qué tiene lugar en una experiencia inefable, privada, acorde con nuestra naturaleza monádica. Pero la conciencia de la experiencia, según la aguda observación de Nietzsche, está lejos de hacer justicia a la experiencia en sí. Si consideramos en detalle lo que afirma en el $\$ 354$ de La gaya ciencia, la instancia de la conciencia queda rebajada a la condición de mero subproducto de la comunicación; y la comunicación, a su vez, aparece como devenida del instinto gregario de la especie, el cual -por último- es interpretado como subproducto de la necesidad y el miedo.

En el mencionado $\$ 354$ de La gaya ciencia ${ }^{7}$ Nietzsche comienza planteando una pregunta incómoda: ¿Para qué sirve la conciencia? Y responde: sirve para que seamos concientes de nosotros mismos. Pero de nuevo, ¿para qué sirve ser concientes de nosotros mismos si ese contenido de conocimiento no puede ser comunicado a los demás? He aquí un conocimiento inútil y, sin embargo, insoslayable, fundamental, puesto que atañe a nuestra condición ontológica. Nietzsche constata que se puede realizar una cantidad enorme de actividades mentales (pensamientos, emociones) y acciones en las que interviene una voluntad alerta y dispuesta sin necesidad de que nada de lo que hacemos entre en la conciencia. La instancia especulativa (reflexiva) que está implícita en el acto de tener conciencia (el así llamado 'saber que') no es necesaria. ¿Para qué puede servirnos esta duplicación de la experiencia que se da en forma de un saber: sé que escucho, sé que esto es un color, sé que estoy triste, etcétera?

${ }^{7}$ Nietzsche, F. 1992: 217-219. 
$\mathrm{Y}$, sin embargo, eso es lo que nos viene propuesto en la experiencia (discriminante) de la música. Por el contrario, permanecer encerrado en la experiencia, en los marcos de la sensación, es para Nietzsche incluso más auténtico, como si el autismo fuese una forma de experiencia válida, o la mónada leibniziana la condición natural del hombre.

De acuerdo, ¿pero de cuál hombre estamos hablando? Del hombre que se ve desde la perspectiva del sujeto. Así, somos mónadas autistas cuando nos consideramos desde la condición subjetiva, es decir, desde nuestros respectivos yos. En esa condición necesariamente nos representamos todos diferentes e inasimilables. Pero, al mismo tiempo, la conciencia de esa singularidad nos coloca fuera de la experiencia en la que nos reconocemos singulares, fuera de la sensación. Desde esta posición extrañada, nos reconocemos todos iguales porque es como si nos viéramos 'desde fuera', desde la perspectiva del objeto. La conciencia vendría a ser un recurso que nos revela nuestro íntimo autismo natural y, por lo contrario, nos habilita a una ilusoria 'objetividad', lo que nos autoriza a pensarnos iguales a nuestros semejantes. Somos iguales, sí, pero sólo en nuestra auto-referencia; luego, iguales pueden ser-aunque nunca vayamos a confirmar este supuesto- nuestros sentimientos, nuestras 'experiencias interiores'. La estética-que en definitiva se ocupa de la experiencia interior, de la vida de los sentimientos, de todo aquello que no puede ser objetivado (por ejemplo, de lo bello)- se ocupa de resolver la tensión excluyente de estas condiciones.

De modo pues que una clave para comprender la experiencia estética sólo cabría hallarla en la extravaganza de Leibniz descrita en su obra póstuma, la Monadología, la cual, pese a sus evidentes connotaciones metafísicas, pinta con sorprendentes matices y coincidencias nuestra condición íntima en relación con nuestras experiencias subjetivas. Según Leibniz, en el mundo no se puede ser sino simple (único, singular, irreductible) o compuesto (por seres únicos, singulares, irreductibles). 'Ser' aquí, como en la antigua Grecia, es haber. Leibniz llama mónadas a las sustancias simples y agregados de mónadas a los entes compuestos, y su descripción de las primeras deja ver que éstas se parecen a los átomos pero no lo son $^{8}$. ¿Qué tienen de especial estas extrañas entidades? En lo que aquí nos interesa: primero, que son únicas e indivisibles precisamente porque son singulares, y para preservarse en la unicidad que las caracteriza, nada puede entrar en ellas, y nada, tampoco, puede salir de ellas. Lo que dentro de ellas acontece, allí queda, herméticamente sellado. Las mónadas sobreviven, pues, pero rodeadas de una muralla infranqueable, en estado de aterradora clausura, como un objeto opaco, liso, sin ventanas. La clausura de las mónadas es la condición que funda y estatuye su diferencia

\footnotetext{
${ }^{8}$ Cosa que sin embargo no consigue disuadir a Gustavo Bueno, quien en sus comentarios preliminares a la edición de la Monadología que consulto, convierte las sutilezas metafísicas de Leibniz en ideas o argumentos cuasi materialistas que -como era previsible- sirven para abonar su propio materialismo.
} 
específica, su razón. Es decir que están autodefinidas o autoconstituidas por su diferencia y singularidad absolutas y, por eso mismo, están condenadas a una suerte de autismo según el cual, nada de lo que las constituye como tales puede ser comunicado a las otras mónadas. En el mundo que forman o que habitan no hay comunicación generada por ellas mismas $\mathrm{y}$, no obstante, hay relación necesaria entre ellas.

Las mónadas son eternas, todas distintas entre sí y todas están sometidas a cambio perpetuo. De modo significativo, Leibniz llama a los cambios que sufren las mónadas 'percepción' (de ellas y de las demás mónadas) y a los cambios que llevan de una percepción a otra 'apercepción' o 'sentimiento'? .

Las mónadas que no sólo perciben sino que además son capaces de acompañar los cambios de una percepción a otra con ayuda de la memoria son almas. Y las almas tienen del mundo infinitas referencias que, inevitablemente, son confusas - por apasionadas- tanto como son distintas las referencias a sí -porque son racionales-y, por ello mismo, incomunicables. El mundo es uno y diverso porque se constituye «como una ciudad contemplada desde lados diferentes [que] parece otra y queda como multiplicada por las perspectivas» ${ }^{10}$, es decir que cada referencia monádica da lugar a infinitos mundos posibles que Dios, en virtud de su Potencia, tiende a poner en armonía, una armonía universal por la que «cualquier sustancia expresa a todas las demás [pero sólo] por las relaciones que tiene con ellas». ${ }^{11}$ Más que al racionalismo crítico kantiano, por lo tanto, Leibniz parece anticiparse al perspectivismo de Nietzsche y, curiosamente, parece oponerse a la tradición nacida por inspiración de su obra ya que, la razón es lo que las mónadas/almas comparten pero sólo en cuanto a que son capaces de establecer relación con ellas mismas, a autorreferirse, mientras que la pasión es lo que comparten por su relación con las demás. En el lugar de la razón común cartesiana nos encontramos con la pasión común. El alma sólo sabe conocer 'por razón', clara y distintamente, lo que atañe a ella misma y eso que conoce, que sabe de sí, no puede comunicarlo. Leibniz lo pone así, al final de $\$ 61$ : «Pero un alma no puede leer en sí misma sino lo que en ella está distintamente representado; no puede desplegar todos sus repliegues a la vez, porque tienden al infinito». ${ }^{12}$ En cambio, puede comunicar su pasión -aunque no el contenido de ésta, que necesariamente pasa por la auto-referencia racional- porque la pasión es lo que pone a la mónada en relación con el mundo.

Vemos aquí una consistencia evidente entre la pasión comunicable de las mónadas y la conciencia que, según afirma Nietzsche, nace de la comunicación. No es la condición que hace posible la comunicación sino aquélla un subproducto de ésta. Para que podamos comunicarnos en nuestra condición de

\footnotetext{
${ }^{9}$ Leibniz, G.W. 1981: §19.

${ }^{10}$ Ibid., $\$ 57$.

${ }^{11}$ Ibid., §59.

${ }^{12}$ Ibid., §61.
} 
mónadas, tenemos que generar esta instancia interior conciente. ¿Y qué dispara la 'necesidad' de la comunicación? La vida de los sentimientos, la penuria, las necesidades materiales. Como dependemos de los demás, estamos obligados a comunicarnos con ellos, y salir así de nuestro autismo. El hombre, animal en peligro, requiere de la conciencia para poder comunicarse con los demás. Quienes se exceden, porque sobresalen (y derrochan comunicación) son los que 'nacen tardíamente, al final de una larga cadena', los artistas, los oradores, los escritores, que, según afirma el tópico, son seres apasionados.

¿Qué es la conciencia? «Una red de conexiones entre hombre y hombre» que se traspone al lenguaje en forma de signos destinados a comunicar al otro que necesitamos ayuda. Para comunicarnos es preciso que sepamos lo que nos falta: saber qué y cómo sentimos, saber qué pensamos, pues «El hombre piensa continuamente, pero no lo sabe».

¿Cómo se hace conciente todo este pensamiento continuo? Trasponiéndolo a palabras por medio de signos de comunicación, de manera que el desarrollo del lenguaje y de la conciencia van de la mano. La conciencia no es una cualidad de la condición individual sino que pertenece a la naturaleza gregaria del hombre. De modo que lo que se conoce 'concientemente' es sólo lo que se puede comunicar, la parte más superficial de la experiencia: el 'genio de la especie'. Nietzsche llama a esta trasposición «fenomenalismo de la conciencia» y advierte que da lugar a «corrupción, falsificación, superficialización y generalización». Al constreñirse al marco de la experiencia observable, objetiva, común (esto es, a todo lo que no es privado) la teoría del conocimiento ha quedado atrapada en los nudos corredizos de la gramática-Nietzsche, con gesto aristocratizante, la llama «metafísica del pueblo»- y dedicada elaborar solamente la parte de nuestra experiencia que surge ya discriminada por la vida gregaria, por la conciencia. Es la conciencia y no la sensación la que discrimina entre el sujeto que conoce y el objeto conocido, y de nuevo es la conciencia la que dictamina que toda otra experiencia (inconciente, fantasía, sueño, locura, confusión) quede reservada al ámbito del sentido íntimo, por llamarlo así, es decir, a la secreta, muda condición de la vida monádica.

Algo de esta rígida determinación entre los órdenes del mundo, el mío y el mundo de los demás, se rompe con ocasión de la música que, paradójicamente, es la más precisa, la más discriminada de mis experiencias. La diferencia entre conciencia y sentimiento es lo que la música, por la vía de una experiencia, nos permite discriminar, dándonos así un conocimiento más auténtico de nosotros mismos. Más precisa o más discriminada es porque, más allá de una imposible descripción subjetiva de lo que sentimos, ofrece al otro un medio para sentir lo mismo y sentirlo de forma apasionada. Enhorabuena entonces, porque es la pasión -y no la razón- la que nos saca del autismo.

Ahora bien, si sólo la música es capaz de permitirnos una discriminación precisa, ¿por qué ha de ser esta discriminación, además, infinita? 
BIBLIOGRAFÍA

Davidson, Donald 2003: Subjetivo, intersubjetivo, objetivo, tr. O. Fernández Prat, Cátedra, Madrid.

Geertz, Clifford 1988: La interpretación de las culturas, tr. A.L. Bixio, revisada por C. Reynoso, Gedisa, Barcelona.

Goodman, Nelson 1976: Languages of art: An approach to a theory of symbols, Hackett, Indianapolis.

Jankélévitch, Vladimir 1983: La musique et l'ineffable, Seuil, Paris.

Leibniz, Gottfried Wilhelm 1981: Monadología, intr. G. Bueno, tr. J. Velarde, Pentalfa, Oviedo.

Nancy, Jean-Luc 2003: El 'hay’ de la relación sexual, tr. F. Vidarte y C. de Peretti, Síntesis, Madrid.

Nietzsche, Friedrich 1992: La ciencia jovial (La gaya ciencia), ed. José Jara, Monte Ávila, Caracas. 